Abstract P-027 Table 1 IONM Alert and Diagnostic Information for All Procedures and 2 Cohort Subgroups

\begin{tabular}{llll}
\hline Category & All Procedures & No MEP Cohort & MEP Cohort \\
\hline True Negatives ( $\mathbf{n})$ & 2200 & 1474 & 726 \\
False Positives $(\mathbf{n})$ & 51 & 27 & 24 \\
True Positives $(\mathbf{n})$ & 24 & 12 & 12 \\
False Negatives $(\mathbf{n})$ & 3 & 2 & 1 \\
Cases with alerts, $\mathbf{n}(\%)$ & $120(5.2 \%)$ & $68(4.5 \%)$ & $52(6.8 \%)$ \\
Sensitivity-\% [95\% Cl] & $88.9[70.8,97.7]$ & $85.7[57.2,98.2]$ & $92.3[34.0,99.8]$ \\
Specificity-\% [95\% Cl] & $97.7[97.0,98.3]$ & $98.2[97.4,98.8]$ & $96.7[95.3,97.9]$ \\
PLR- Value [95\% Cl] & $39.2[29.0,53.1]$ & $47.7[31.0,73.3]$ & $28.9[18.9,44.1]$ \\
NLR- Value [95\% Cl] & $0.11[0.04,0.33]$ & $0.15[0.04,0.52]$ & $0.08[0.01,0.52]$ \\
\hline
\end{tabular}

Abstract P-027 Table 2 Odds Ratios (OR) for New Deficit Based on Signal Change and Complication. Odds Ratio referent was C

\begin{tabular}{lll}
\hline Cause of Change & Attenuation- OR [95\% Cl] & Loss -OR [95\% Cl] \\
\hline Any Complication $(n=83)$ & $210.9^{*}[44.3,1003.5]$ & $1437.3^{*}[297.3,6948.2]$ \\
Rupture $(n=16)$ & $808.5^{*}[105.1,62220.8]$ & $8624.0^{*}[708.7,10494.8]$ \\
Embolus $(n=22)$ & $308.0^{*}[37.9,2504]$. & $924.0^{*}[158.3,5392.1$ \\
Instrumentation $(n=38)$ & $34.8^{* *}[3.1,393.6]$ & $539.0^{*}[60.2,4824.5]$ \\
Vasospasm $(n=7)$ & $808.5^{*}[105.1,6220.8]$ & N/A \\
\hline
\end{tabular}

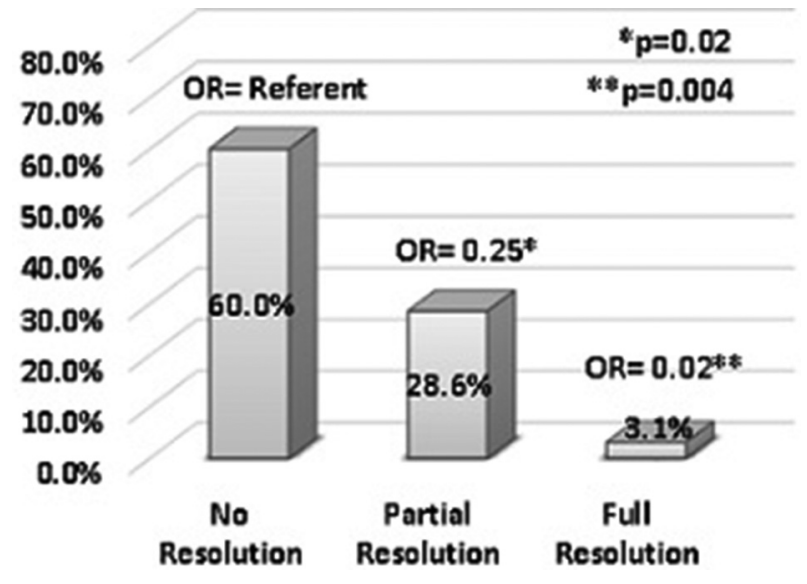

Abstract P-027 Figure 1 Rate and Odds Ratios (OR)for New Deficit After IONM Change Associated with Perioperatve Arterial Complication as a Function of the Resolution of the Change.

a new deficit significantly increased as a function of the magnitude of IONM change and type of complication (table 2). For procedures with changes associated with a perioperative complication $(n=83)$, the rate of new neurologic deficit was $60 \%$ if the change remained unresolved $(n=18 / 30)$. However, the rate and risk of new deficit was significantly decreased if a change was partially resolved $(28.6 \%, \mathrm{n}=6 / 21, \mathrm{OR}=0.27)$, and was dramatically decreased if fully resolved $(3.1 \%, n=1$ / 32, $\mathrm{OR}=0.02$ ) (figure 1).

Conclusions IONM has excellent diagnostic accuracy during cerebral neuroendovascular procedures. Both the magnitude and putative cause of IONM change provide diagnostic and prognostic information. Perioperative complications are significantly less likely to result in postoperative dysfunction if there is a timely diagnosis and intervention that results in the resolution of IONM signal change.
Disclosures W. Wilent: None. S. Tjoumakaris: None. P. Jabbour: None. M. Gooch: None. R. Rosenwasser: None. W. Kim: None. J. English: None. O. Belyakina: None. E. Korsgaard: None. J. Cohen: None. A. Sestokas: None.

\section{P-028 WEB COLOMBIAN MULTICENTER EXPERIENCE (WEB. COM) : CLINICAL AND RADIOLOGICAL MID- TERM RESULTS IN THE TREATMENT OF INTRACRANIAL ANEURYSMS}

${ }^{1} \mathrm{~B}$ Pabon*, ${ }^{1} \mathrm{C}$ Diaz, ${ }^{1} \mathrm{O}$ Vargas, ${ }^{1} \mathrm{~J} M$ Mejia, ${ }^{2} \mathrm{~J}$ Fernandez, ${ }^{3} \mathrm{R}$ Almeida, ${ }^{4} \mathrm{~N}$ Lobelo. ${ }^{1}$ Neuroendovascular Surgery, Angioteam - Clinica del Norte, Medellin, Colombia; ${ }^{2}$ Neuroendovascular Surgery, Clinica Costa azul, Medellin, Colombia; ${ }^{3}$ Neuroendovascular Surgery, Neurodinamia, Cartagena, Colombia; ${ }^{4}$ Neuroendovascular Surgery, Clinica Colombia, Bogota, Colombia

\subsection{6/neurintsurg-2019-SNIS.64}

Introduction Woven EndoBridge (WEB) is a novel device for the treatment of ruptured and unruptured bifurcation aneurysms. To our knowledge none experience in Latin America has been reported. In the present study, we present a multicenter early experience and mid-term follow data for patients treated with WEB.

Materials and methods 32 consecutive patients with 33 intracranial aneurysms underwent endovascular treatment using WEB between March 2016 and February 2019 in four different centers and cities. We retrospectively evaluated the angiographic results at the end of the procedure and at follow-up, technical considerations, the clinical status and complications. Results

All attempted cases were treated, but one. Non procedural rupture was recorded. Aneurysm locations were internal carotid artery bifurcation $(n=6)$, middle cerebral artery $(n=17)$, anterior communicating artery $(\mathrm{n}=4)$, Basilar Trunk $(\mathrm{n}=1)$ and basilar tip $(n=5)$. Eight patients were treated in the setting of acute subarachnoid hemorrhage. 1.12 Devices per aneurysm. 32 of 33 cases treated with web without coils. In five cases was necessary additional stenting- 15\%. 16/29 with angiographic follow-up, complete occlusion A-B in 15/16. Procedural mean time $17 \mathrm{~min}$. Conclusion

This series is at the moment the only, multicenter, Latin American experience of patients treated with WEB. The treatment shows a good safety and efficacy in the endovascular treatment of WNB intracranial aneurysms.

Disclosures B. Pabon: 2; C; Microvention, Medtronic, Stryker. C. Diaz: None. O. Vargas: None. J. Mejia: None. J. Fernandez: None. R. Almeida: 2; C; Microvention. N. Lobelo: None.

\section{P-029 LONGITUDINAL MONITORING OF FLOW-DIVERTING STENT TISSUE COVERAGE AFTER IMPLANT USING NEUROVASCULAR HIGH FREQUENCY OPTICAL COHERENCE TOMOGRAPHY}

J Caroff*, GJ Ughi, R King, M Marosfoi, E Langan, M Gounis. New England Center for Stroke Research, University of Massachusetts Medical School, Worcester, MA

\subsection{6/neurintsurg-2019-SNIS.65}

Introduction High frequency optical coherence tomography (HF-OCT) is an intra-vascular imaging modality designed for cerebrovascular anatomy. With a spatial resolution approaching 